\title{
Carbonate-Catalyzed Reverse Water-Gas Shift to Produce Gas Fermentation Feedstocks for Renewable Liquid Fuel Synthesis
}

\author{
Chastity S. Li ${ }^{\dagger}$, Amy D. Frankhouser ${ }^{\dagger}$, and Matthew W. Kanan* \\ Department of Chemistry, Stanford University, Stanford, California 94305, United States \\ ${ }^{\dagger}$ Denotes equal contribution
}

\section{Summary}

Carbon-neutral liquid fuel generation is essential for decarbonizing sectors that cannot readily electrify. Recently commercialized acetogenic gas fermentation offers an alternative to conventional biofuels that circumvents efficiency limitations and land requirements, provided the requisite $\mathrm{H}_{2} / \mathrm{CO}$ feedstocks can be generated efficiently using renewable inputs. $\mathrm{CO}_{2}$ electrolysis to $\mathrm{CO}$ is under development for this purpose, but suffers from scalability challenges and impurity sensitivity. We describe an alternative that utilizes dispersed alkali carbonates as reverse water-gas shift (RWGS) catalysts to convert $\mathrm{H}_{2}$ and $\mathrm{CO}_{2}$ to an appropriate ratio of $\mathrm{CO} / \mathrm{CO}_{2} / \mathrm{H}_{2}$ for acetogenic fermentation. Using a fixed bed reactor operating at industrially relevant space velocity, we demonstrate equilibrium RWGS conversion starting at $410{ }^{\circ} \mathrm{C}$ that remains stable over days, even with $50 \mathrm{ppm}_{2} \mathrm{~S}$ impurity. The combination of carbonate-catalyzed RWGS, water electrolysis, and gas fermentation could convert electricity to ethanol with nearly $50 \%$ energy efficiency, providing a compelling option for renewable liquid fuel production.

\section{Introduction}

Liquid fuels currently provide $30 \%$ of global energy demand and are likely to remain a major pillar of global energy supply for many decades. ${ }^{1,2}$ Achieving a carbon-neutral energy system will therefore likely require replacing fossil-derived liquid fuels with renewable alternatives made from $\mathrm{CO}_{2}, \mathrm{H}_{2} \mathrm{O}$, and lowcarbon energy. At present, the only significant source of renewable liquid fuels are biofuels produced from agricultural products (e.g. corn, sugarcane, palm oil). Biofuel production is limited by the low efficiency of natural photosynthesis, which has a global average of $\sim 0.2 \%{ }^{3}$ As they are currently produced, biofuels also compete with food for arable land, which can lead to environmentally devastating land use changes. The conversion of renewable electric power to liquid fuel is an attractive alternative because it could take advantage of the relatively high efficiency and falling costs of low-carbon electricity and it would not require arable land. Renewable methanol synthesis has been demonstrated at the multi-kiloton $\mathrm{yr}^{-1} \mathrm{scale}$ by combining geothermal-powered water electrolysis with thermal catalysis of $\mathrm{CO}_{2}$ hydrogenation to methanol. ${ }^{4}$ A number of power-to-liquid fuel demonstration plants have been developed that utilize FischerTropsch catalysis to produce hydrocarbon fuels. Starting from $\mathrm{CO}_{2}$, these systems utilize high-temperature $\left(>800{ }^{\circ} \mathrm{C}\right)$ reverse water-gas shift $(\mathrm{RWGS})$ or solid oxide electrolysis to prepare the syngas $\left(\mathrm{CO}+\mathrm{H}_{2}\right)$ required for Fischer-Tropsch catalysis and produce a wide range of hydrocarbon products. ${ }^{5}$ Despite decades of research, the efficient and selective production of a single multi-carbon fuel remains a major challenge.

Anaerobic gas fermentation is a process in which acetogenic microorganisms convert a $\mathrm{C}_{1}$ feedstock $(\mathrm{CO}$ and/or $\left.\mathrm{CO}_{2}\right)$ and an energy source $\left(\mathrm{CO}\right.$ and/or $\left.\mathrm{H}_{2}\right)$ into chemicals and fuels. ${ }^{6}$ Gas fermentation has been developed in industry over the past 20 years and recently commercialized as a technology to produce ethanol fuel from gas streams that are rich in $\mathrm{CO}$, such as industrial off-gases or pyrolyzed biomass. The first commercial-scale gas fermentation plant uses CO-rich steel mill exhaust as the feedstock and has capacity of 46,000 tons ethanol $\mathrm{yr}^{-1}$; several more plants of comparable scale are under construction. ${ }^{7}$ Ethanol can be blended with gasoline for light vehicles or upgraded to jet fuel using established technologies. ${ }^{8}$ These developments have created a new opportunity for power-to-liquid fuel synthesis starting from $\mathrm{CO}_{2}$ and $\mathrm{H}_{2} \mathrm{O}$. The basic idea is to use renewable power to convert $\mathrm{CO}_{2}$ and $\mathrm{H}_{2} \mathrm{O}$ into a suitable 

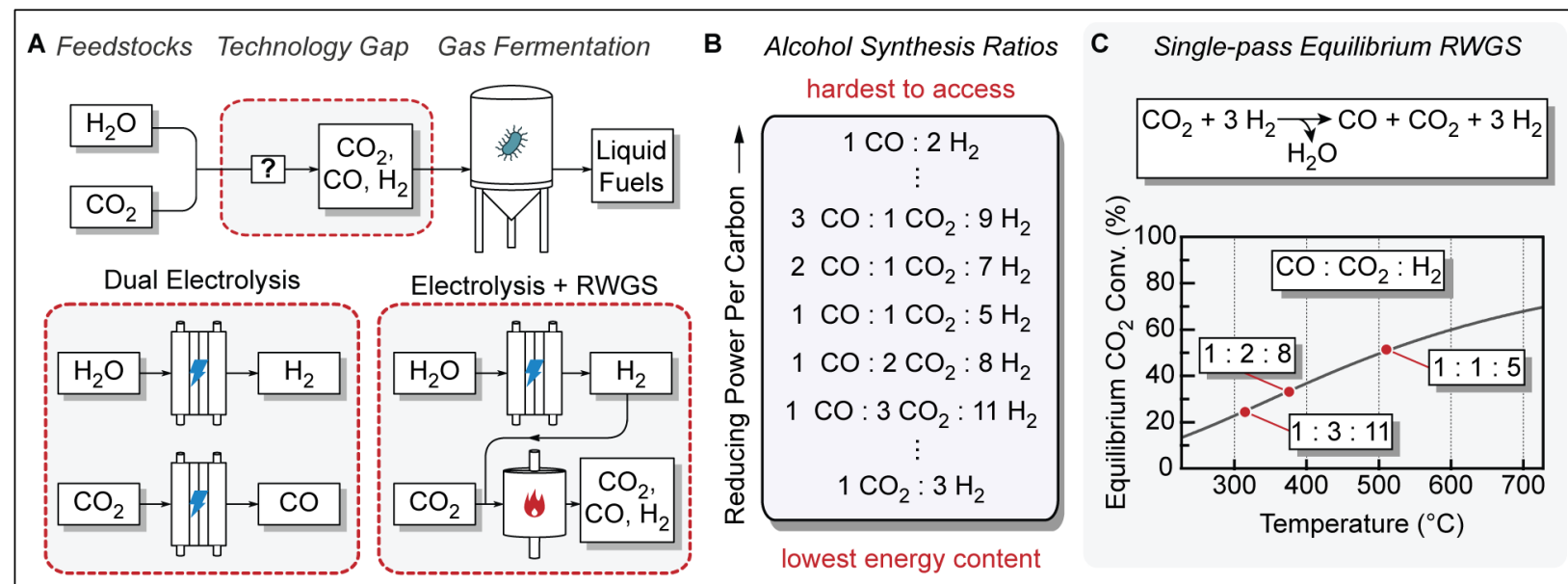

Figure 1: Hybrid synthetic/biological power-to-liquid-fuel. A) Schematic of $\mathrm{C}_{2+}$ liquid fuel synthesis from $\mathrm{CO}_{2}$ and $\mathrm{H}_{2} \mathrm{O}$ using gas fermentation. The gas fermentation feedstock could be prepared by a combination of $\mathrm{H}_{2} \mathrm{O}$ and $\mathrm{CO}_{2}$ electrolysis or $\mathrm{H}_{2} \mathrm{O}$ electrolysis combined with RWGS. B) Gas ratios with the appropriate stoichiometry for saturated alcohol synthesis. Ratios with moderate $\mathrm{CO}$ content can be accessed by low-temperature RWGS and support high fermentation yields; C) Output $\mathrm{CO}: \mathrm{CO}_{2}: \mathrm{H}_{2}$ gas ratios for a RWGS reactor operating at equilibrium single-pass conversion with an input ratio of $1: 3 \mathrm{CO}_{2}: \mathrm{H}_{2}$.

energy-rich $\mathrm{H}_{2} / \mathrm{CO} / \mathrm{CO}_{2}$ feedstock gas and then use gas fermentation to convert this feedstock into ethanol (Fig. 1A). This hybrid approach is appealing because a synthetic system is used to perform the upfront conversion of renewable into chemical energy (the gas feedstock), which circumvents the efficiency limitations and land requirements of natural photosynthesis, but engineered microbes are used to perform selective $\mathrm{C}-\mathrm{C}$ bond formation, which is a perennial struggle for synthetic gas-to-liquid conversion systems. With the growth of renewable electricity and the advent of commercial gas fermentation, the viability of such a process hinges on efficient preparation of the feedstock gas from industrially relevant $\mathrm{CO}_{2}$ streams.

The strategy used to prepare the feedstock gas must be informed by the gas ratio needed to sustain robust alcohol synthesis. The stoichiometry for $\mathrm{CO}_{2}$ hydrogenation to any saturated acyclic alcohol corresponds to a $1: 3 \mathrm{CO}_{2}: \mathrm{H}_{2}$ ratio, whereas $\mathrm{CO}$ hydrogenation to alcohol requires a $1: 2 \mathrm{CO}: \mathrm{H}_{2}$ ratio. With $\mathrm{CO}_{2}, \mathrm{H}_{2} \mathrm{O}$, and energy as the primary inputs, a $1: 3 \mathrm{CO}_{2}: \mathrm{H}_{2}$ feedstock is the easiest to prepare because it requires only water electrolysis. Unfortunately, a 1:3 $\mathrm{CO}_{2}: \mathrm{H}_{2}$ feedstock is not suitable for commercial alcohol production because most acetogens produce only acetate from this mixture and those that do produce alcohol have low growth rates, low productivity, and modest selectivity. ${ }^{9,10}$ A 1:2 CO: $\mathrm{H}_{2}$ feedstock supports high microbial growth and alcohol productivity, but this mixture is the most difficult to prepare from $\mathrm{CO}_{2}$ and $\mathrm{H}_{2} \mathrm{O}$. In between 1:3 $\mathrm{CO}_{2}: \mathrm{H}_{2}$ and 1:2 $\mathrm{CO}: \mathrm{H}_{2}$ are any number of $\mathrm{CO}: \mathrm{CO}_{2}: \mathrm{H}_{2}$ ratios with the appropriate stoichiometry for alcohol synthesis (Fig. 1B). Recent developments indicate that relatively low $\mathrm{CO}: \mathrm{CO}_{2}$ ratios are sufficient for high gas fermentation alcohol productivity. Laboratory studies have shown that supplementing a $1: 3 \mathrm{CO}_{2}: \mathrm{H}_{2}$ feedstock with just 0.1 equivalent $\mathrm{CO}$ (i.e. a 0.1:1:3 $\mathrm{CO}: \mathrm{CO}_{2}: \mathrm{H}_{2}$ ratio) in gas fermentation with $C$. autoethanogem increases the volumetric ethanol productivity by $5 \times$ and doubles the ethanol:acetate ratio. ${ }^{11}$ Commercially viable gas fermentation has been demonstrated using gasified agricultural residues as the feedstock, which typically has a $\mathrm{CO}: \mathrm{CO}_{2}$ ratio of $\sim 1: 1{ }^{12}$ Thus, gas fermentation can utilize relatively $\mathrm{CO}_{2}$-rich gas streams that are not useful in other gas-to- $\mathrm{C}_{2}+$ technologies such as Fischer-Tropsch.

While the opportunity to utilize gas fermentation in a power-to-fuel process has been widely recognized, the only technology that has received substantial attention for preparing the requisite $\mathrm{CO}$ component is lowtemperature $\mathrm{CO}_{2}$ electrolysis. ${ }^{13-16}$ In this approach, a $\mathrm{CO}_{2}$ electrolyzer would be combined with a $\mathrm{H}_{2} \mathrm{O}$ 
electrolyzer to prepare a target $\mathrm{CO} / \mathrm{CO}_{2} / \mathrm{H}_{2}$ gas feedstock (Fig. 1A, Dual Electrolysis). Although significant progress has been made over the past decade, $\mathrm{CO}_{2}$ electrolysis is still in an early stage of development and faces a number of major science and engineering challenges for use in fuel production (see below). An alternative strategy is to use $\mathrm{H}_{2} \mathrm{O}$ electrolysis to produce $\mathrm{H}_{2}$ and then convert $\mathrm{CO}_{2}$ and $\mathrm{H}_{2}$ into a $\mathrm{CO} / \mathrm{CO}_{2} / \mathrm{H}_{2}$ feedstock by performing Reverse Water-Gas Shift (RWGS; Eq. 1) in a fixed-bed reactor (Fig. 1A, RWGS + Electrolysis). Water electrolysis is a well-developed and rapidly growing commercial technology; proton exchange membrane (PEM) electrolyzers can operate at $\sim 80 \%$ energy efficiency at $2 \mathrm{~A} \mathrm{~cm}^{-2}{ }^{27,18}$ While RWGS has limited applications at present, the Water-Gas Shift (WGS) reaction (opposite of RWGS) is already performed industrially to adjust the gas ratio for $10^{8}$ ton $\mathrm{yr}^{-1}$ steam reforming processes. ${ }^{19}$

$$
\begin{aligned}
& \mathrm{CO}_{2}+\mathrm{H}_{2} \rightarrow \mathrm{CO}+\mathrm{H}_{2} \mathrm{O} \quad\left(\Delta H_{298 K}^{o}=42.1 \mathrm{kj} \mathrm{mol}^{-1}\right) \\
& \mathrm{CO}_{2}+4 \mathrm{H}_{2} \rightarrow \mathrm{CH}_{4}+2 \mathrm{H}_{2} \mathrm{O}\left(\Delta H_{298 K}^{o}=-252.9 .1 \mathrm{kj} \mathrm{mol}^{-1}\right)
\end{aligned}
$$

The use of RWGS to prepare gas fermentation feedstocks requires a catalyst that meets a number of criteria. To minimize the process complexity and energy demand, the catalyst should operate at the equilibriumlimited single-pass conversion with an industrially relevant space velocity at the temperature needed to produce a suitable gas ratio. With an input of $1: 3 \mathrm{CO}_{2}: \mathrm{H}_{2}$, the equilibrium-limited RWGS conversion corresponds to a CO: $\mathrm{CO}_{2}: \mathrm{H}_{2}$ gas ratio of 1:1:5 at $504{ }^{\circ} \mathrm{C}$. Given the apparent commercial viability of this ratio, we take $504{ }^{\circ} \mathrm{C}$ to be the maximum target temperature (Fig. 1C). Further developments in gas fermentation processes may make lower ratios and correspondingly lower temperatures viable, e.g. 1:2:8 at $375{ }^{\circ} \mathrm{C}$. The RWGS catalyst must also avoid the thermodynamically preferred hydrogenation reaction to produce $\mathrm{CH}_{4}$ (Eq. 2). Any $\mathrm{CH}_{4}$ produced by the hydrogenation reactor would need to be vented or combusted to prevent its accumulation because acetogens cannot metabolize $\mathrm{CH}_{4}$. Venting even a small percentage of $\mathrm{CH}_{4}$ negates the carbon benefit because of the $25 \times$ higher global warming potential of $\mathrm{CH}_{4}$ compared to $\mathrm{CO}_{2}{ }^{20}$ Finally, the RWGS will need to operate in the presence of $\mathrm{H}_{2} \mathrm{~S}$ impurities. $\mathrm{H}_{2} \mathrm{~S}$ is a significant impurity in some of the most accessible emissions sources for $\mathrm{CO}_{2}$ utilization, including offgases from ammonia production and corn ethanol fermentation. ${ }^{21} \mathrm{H}_{2} \mathrm{~S}$ is also produced in the gas fermentation process itself and would be exposed to the RWGS catalyst because recycle loops are needed to maximize gas conversion.

Previously reported RWGS catalysts include supported transition metal nanoparticles, metal oxides, metal carbides, and metal sulfides. ${ }^{22}$ Among these many options, there is no single catalyst that has been shown to satisfy all of the above criteria for gas fermentation applications. Most catalysts have been developed for high-temperature RWGS $\left(\geq 600{ }^{\circ} \mathrm{C}\right)$ and only a small subset have substantial activity in the $300{ }^{\circ} \mathrm{C}-500$ ${ }^{\circ} \mathrm{C}$ regime targeted here. To our knowledge, the most active known catalyst at these temperatures consists of Pt nanoparticles dispersed on $\mathrm{TiO}_{2}\left(\mathrm{Pt} / \mathrm{TiO}_{2}\right)$, which has been reported to achieve near-equilibrium RWGS conversion with a 1:1 CO $2: \mathrm{H}_{2}$ input ratio at a weight hourly space velocity (WHSV) of 12,000 ml $\mathrm{g}^{-1} \mathrm{~h}^{-1}$ from $300{ }^{\circ} \mathrm{C}-600{ }^{\circ} \mathrm{C} .{ }^{23}$ However, as shown below, $\mathrm{Pt} / \mathrm{TiO}_{2}$ produces significant amounts of $\mathrm{CH}_{4}$ with a 1:3 $\mathrm{CO}_{2}: \mathrm{H}_{2}$ feed. Metal carbides $\left(\mathrm{Mo}_{x} \mathrm{C}, \mathrm{W}_{x} \mathrm{C}\right)$ have shown promising RWGS activity at low temperatures and various strategies have been described to optimize $\mathrm{CO}$ selectivity. ${ }^{24-26} \mathrm{However} \mathrm{CH}_{4}$ formation still accounts for a few percent of the $\mathrm{CO}_{2}$ conversion with optimized metal carbide materials in long-term experiments. Moreover, while metal carbides are considered to be sulfur-tolerant catalysts in other transformations, rapid poisoning by low-ppm $\mathrm{H}_{2} \mathrm{~S}$ has been observed for $\mathrm{Mo}_{x} \mathrm{C}$ under WGS conditions. ${ }^{27}$ The mixed oxide formed from $\mathrm{ZnO}$ and $\mathrm{Cr}_{2} \mathrm{O}_{3}\left(\mathrm{ZnO} / \mathrm{Cr}_{2} \mathrm{O}_{3}\right)$, which is a well-known syngasto-methanol catalyst at $<300{ }^{\circ} \mathrm{C}$, is a selective RWGS catalyst at $>400{ }^{\circ} \mathrm{C}$ and has been reported to achieve equilibrium RWGS conversion at $500{ }^{\circ} \mathrm{C}$ and a gas hourly space velocity of $15,000 \mathrm{~h}^{-1} \cdot{ }^{28}$ However, $\mathrm{ZnO} / \mathrm{Cr}_{2} \mathrm{O}_{3}$ is also susceptible to $\mathrm{H}_{2} \mathrm{~S}$ poisoning, ${ }^{29}$ although the kinetics of poisoning are slower than for 
most transition metal catalysts. Lanthanum oxysulfides and $\mathrm{Mo}_{2} \mathrm{~S}$ are sulfur tolerant RWGS catalysts, but both of these have very low activity at $\leq 500^{\circ} \mathrm{C} .^{30,31}$

We recently showed that alkali carbonates $\left(\mathrm{M}_{2} \mathrm{CO}_{3}\right)$ dispersed in mesoporous materials serve as base promoters for benzene carboxylation with $\mathrm{CO}_{2}$ to form benzoate at $\sim 400$ ${ }^{\circ} \mathrm{C} .{ }^{32}$ Dispersion disrupts the crystal lattice of $\mathrm{M}_{2} \mathrm{CO}_{3}$, rendering an amorphous, high-surface area material that deprotonates the benzene $\mathrm{C}-\mathrm{H}$ bond at $\sim 400{ }^{\circ} \mathrm{C}$, generating a putative carbanion intermediate that reacts with $\mathrm{CO}_{2}$. Since benzene has the same gas phase acidity (heterolytic bond dissociation energy) as $\mathrm{H}_{2}{ }^{33}$ we
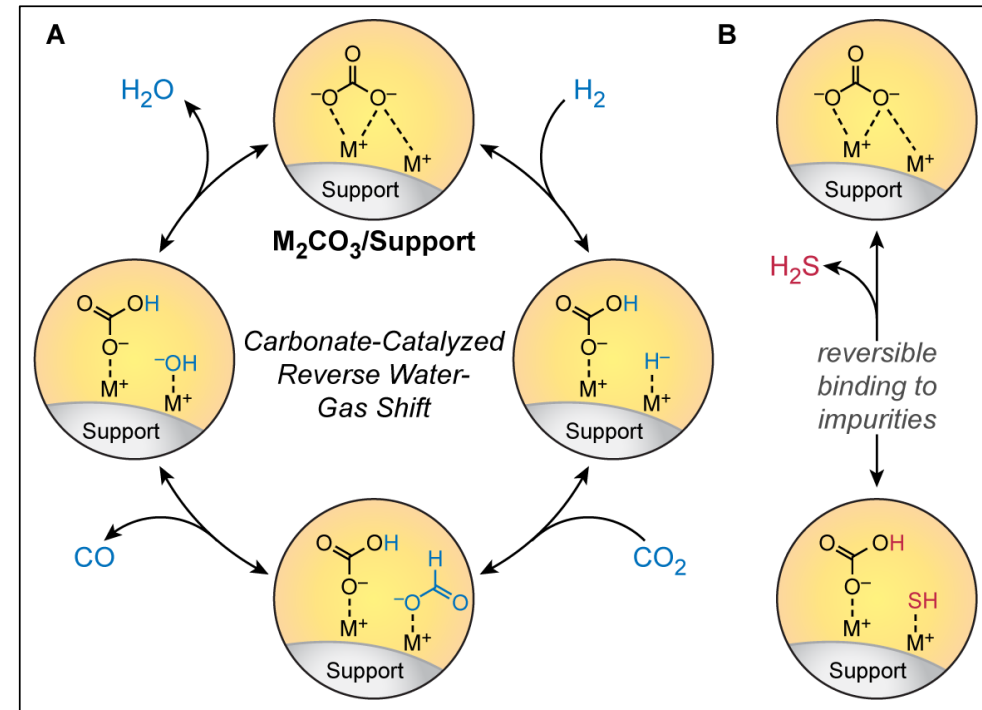

Figure 2: Carbonate-catalyzed RWGS. A) Proposed catalytic cycle wherein dispersed carbonate deprotonates $\mathrm{H}_{2}$, and reduces $\mathrm{CO}_{2}$ to $\mathrm{CO}$ via a formate intermediate. B) Reversible deprotonation of $\mathrm{H}_{2} \mathrm{~S}$ precludes catalyst poisoning. hypothesized that dispersed carbonates would catalyze RWGS in a similar temperature regime via a cycle involving $\mathrm{H}_{2}$ carboxylation to form formate $\left(\mathrm{HCO}_{2}{ }^{-}\right)$and subsequent dehydroxylation to form $\mathrm{CO}$ (Fig. 2A). Because alkali cations have very weak affinity for $\mathrm{CO},{ }^{34}$ dispersed carbonates should be incapable of reducing $\mathrm{CO}$ further to $\mathrm{CH}_{4}$ during RWGS. While $\mathrm{M}_{2} \mathrm{CO}_{3}$ is likely to react with $\mathrm{H}_{2} \mathrm{~S}$ through acid-base chemistry, this process should be completely reversible under RWGS conditions because alkali sulfides are not stable in the presence of $\mathrm{H}_{2} \mathrm{O}$ (Fig. 2B) ${ }^{35,36}$ Thus, we further hypothesized that dispersed carbonates would be highly selective and sulfur tolerant, making them well-suited for gas fermentation applications.

Early studies by Amenomiya and co-workers reported RWGS kinetics for catalysts composed of alkali oxides $\left(\mathrm{M}_{2} \mathrm{O}\right)$ dispersed on $\mathrm{Al}_{2} \mathrm{O}_{3},{ }^{37}$ which can be expected to form dispersed carbonates upon $\mathrm{CO}_{2}$ exposure. A linear correlation was observed between the reaction kinetics and the coverage of a surface formate species detected by IR. However, these studies were performed in a closed-loop reactor with active $\mathrm{H}_{2} \mathrm{O}$ removal because $\mathrm{H}_{2} \mathrm{O}$ was reported to completely inhibit RWGS on $\mathrm{Al}_{2} \mathrm{O}_{3}$ at low partial pressures. ${ }^{38}$ We have also previously observed RWGS products under batch $\mathrm{CO}_{2}$ hydrogenation conditions with unsupported, hydrated $\mathrm{Cs}_{2} \mathrm{CO}_{3}$ salts at elevated temperature and pressure. ${ }^{39}$ To our knowledge, RWGS catalysis at steady-state using a dispersed carbonate material as the catalyst has not previously been evaluated. Here we show that $\mathrm{Cs}_{2} \mathrm{CO}_{3}$ dispersed in mesoporous supports is a highly active, selective, durable, and sulfur-tolerant RWGS in the temperature regime targeted for gas fermentation applications. A preliminary analysis indicates that integrating this catalysis with $\mathrm{H}_{2} \mathrm{O}$ electrolysis and gas fermentation would enable nearly $50 \%$ power-to-liquid fuel energy conversion efficiency. The simplicity and robustness of these catalysts could greatly facilitate scale-up for fuel applications.

\section{Results and Discussion}

\section{Evaluation of Carbonate-Catalyzed RWGS}

Materials with a high degree of carbonate dispersion that are suitable for fixed bed reactors can be easily prepared from commercially available mesoporous $\mathrm{TiO}_{2}, \gamma-\mathrm{Al}_{2} \mathrm{O}_{3}$, and granular activated carbon (GAC) supports using incipient wetness impregnation. The surface areas of the support materials determined by 

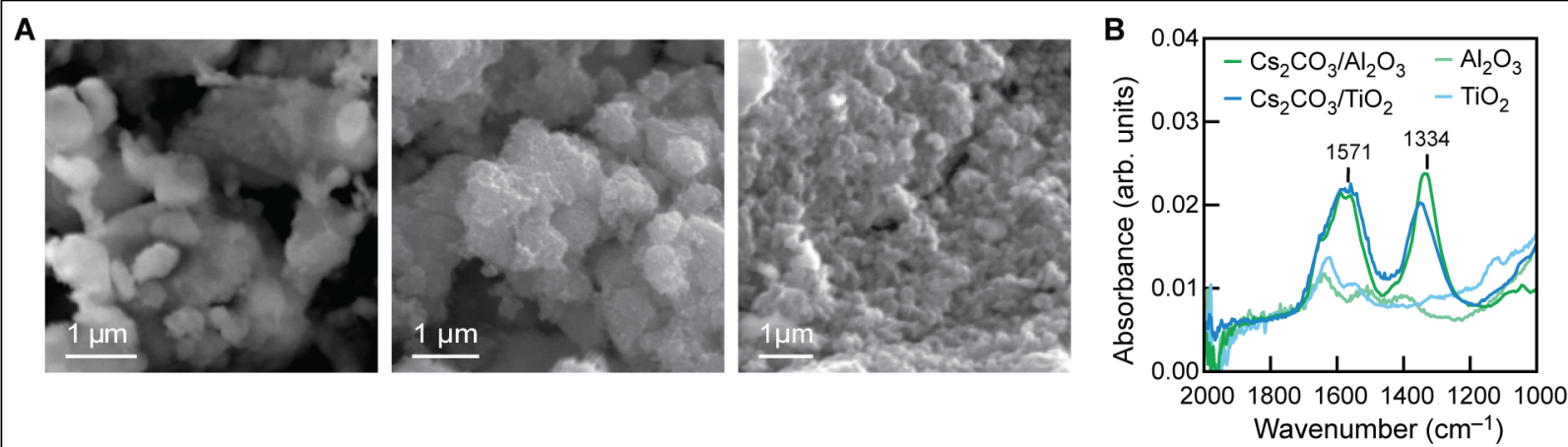

Figure 3: Dispersed carbonate catalysts. A) SEMs of $\mathrm{Cs}_{2} \mathrm{CO}_{3}$ dispersed in different supports. From left to right: $\mathrm{Cs}_{2} \mathrm{CO}_{3} / \mathrm{Al}_{2} \mathrm{O}_{3}, \mathrm{Cs}_{2} \mathrm{CO}_{3} / \mathrm{TiO}_{2}, \mathrm{Cs}_{2} \mathrm{CO}_{3} / \mathrm{GAC}$. B) IR spectra of $\mathrm{Cs}_{2} \mathrm{CO}_{3}$ dispersed in oxide supports in the $\mathrm{C}-\mathrm{O}$ stretching region. Spectra obtained after continuous steady state operation over $44 \mathrm{~h}$ at $3: 1 \mathrm{H}_{2}: \mathrm{CO}_{2}(\mathrm{WHSV}=4800$ $\left.\mathrm{ml} \mathrm{g}^{-1} \mathrm{~h}^{-1}\right), 10$ bar, $468{ }^{\circ} \mathrm{C}$. Peak splitting is consistent with bridging/bidentate coordination of $\mathrm{CO}_{3}{ }^{2-}$.

Brunauer-Emmett-Teller (BET) $\mathrm{N}_{2}$ sorption were $153 \mathrm{~m}^{2} / \mathrm{g}, 251 \mathrm{~m}^{2} / \mathrm{g}$, and $608 \mathrm{~m}^{2} / \mathrm{g}$, respectively (Table S1). Single loadings of an aqueous $\mathrm{Cs}_{2} \mathrm{CO}_{3}$ solution were used to prepare $\mathrm{Cs}_{2} \mathrm{CO}_{3}$ dispersed in $\mathrm{TiO}_{2}(\mathrm{Cs}-$ $\left.{ }_{2} \mathrm{CO}_{3} / \mathrm{TiO}_{2}\right)$ and $\mathrm{Cs}_{2} \mathrm{CO}_{3}$ dispersed in $\gamma-\mathrm{Al}_{2} \mathrm{O}_{3}\left(\mathrm{Cs}_{2} \mathrm{CO}_{3} / \mathrm{Al}_{2} \mathrm{O}_{3}\right)$ with final $\mathrm{Cs}_{2} \mathrm{CO}_{3}$ of $23 \mathrm{wt} \%$ and $34 \mathrm{wt} \%$, respectively. A single loading of a methanolic $\mathrm{Cs}_{2} \mathrm{CO}_{3}$ solution was used to prepare $\mathrm{Cs}_{2} \mathrm{CO}_{3}$ dispersed in GAC $\left(\mathrm{Cs}_{2} \mathrm{CO}_{3} / \mathrm{GAC}\right)$ with a lower loading of $10 \mathrm{wt} \%$ because of the reduced solubility of $\mathrm{Cs}_{2} \mathrm{CO}_{3}$ in methanol (Fig. 3A). Infrared (IR) spectroscopy was performed to qualitatively assess the degree of carbonate surface dispersion and the nature of the $\mathrm{CO}_{3}{ }^{2-}$ coordination environments. ${ }^{32,40}$ These measurements were performed after long RWGS runs (see below) to allow for any rearrangements that occur during operation. For both materials, the $\mathrm{C}-\mathrm{O}$ stretching region is dominated by a pair of broad peaks centered at $\sim 1570$ and $\sim 1340 \mathrm{~cm}^{-1}$, which is indicative of reduced symmetry in the $\mathrm{CO}_{3}{ }^{2-}$ coordination environment compared to the bulk crystalline lattice (Fig. S2). The magnitude of the peak splitting is consistent with a bidentate and/or bridging coordination to the $\mathrm{Cs}^{+}$cation, as has been assigned previously based on IR spectra of $\mathrm{K}_{2} \mathrm{CO}_{3}$ dispersed in $\gamma-\mathrm{Al}_{2} \mathrm{O}_{3} .{ }^{41}$ These results indicate that a dispersed, non-crystalline carbonate is stable on the $\mathrm{Cs}_{2} \mathrm{CO}_{3} / \mathrm{TiO}_{2}$ and $\mathrm{Cs}_{2} \mathrm{CO}_{3} / \mathrm{Al}_{2} \mathrm{O}_{3}$ materials under RWGS conditions. Excessive scattering by the GAC support material prevented IR characterization of $\mathrm{Cs}_{2} \mathrm{CO}_{3} / \mathrm{GAC}$.

$\mathrm{CO}_{2}$ hydrogenation reactions were carried out in a custom stainless steel fixed bed reactor equipped with a vertical furnace (Fig. S1). For each reaction, $500 \mathrm{mg}$ of catalyst was loaded into the reactor and heated while exposing to a flowing mixture of $\mathrm{H}_{2}$ and $\mathrm{CO}_{2}$ gas (10 bar pressure, 3:1 $\mathrm{H}_{2}: \mathrm{CO}_{2}$ ) at a rate of $40 \mathrm{sccm}$, which corresponds to a WHSV of $4,800 \mathrm{ml} \mathrm{g}^{-1} \mathrm{~h}^{-1}$. This WHSV was chosen to be within the range of values that are used in industrial applications of heterogeneously catalyzed gas-phase reactions while enabling convenient evaluation of multiple materials over long-duration experiments (see below). Water produced in the reaction was collected in a gravity trap, while the gaseous products were passed to a gas chromatograph (GC) for analysis at regular intervals. $\mathrm{CO}, \mathrm{CO}_{2}$, and $\mathrm{CH}_{4}$ were quantified in each $\mathrm{GC}$ analysis based on independent calibration standards.

An initial survey was performed by stepping the reactor temperature from 355 to $515{ }^{\circ} \mathrm{C}$ in $25-30{ }^{\circ} \mathrm{C}$ increments, with each temperature step held for $3 \mathrm{~h}$. These experiments revealed that the dispersed carbonates are highly active and selective RWGS catalysts at temperatures greater than $\sim 400{ }^{\circ} \mathrm{C}$. Figure 4A compares the steady-state $\mathrm{CO}$ yield at each temperature step for dispersed carbonates, unloaded oxide supports, and a commercial Pt catalyst. A control experiment with the empty reactor showed a small amount of $\mathrm{CO}$ production across the temperature screen, which reflects low levels of RWGS activity catalyzed by the stainless steel reactor walls. The unloaded $\mathrm{TiO}_{2}$ support showed moderate $\mathrm{CO}$ production above this 
background level, but was still far below the equilibriumlimited conversion even at the highest temperature evaluated. By contrast, the $\mathrm{Cs}_{2} \mathrm{CO}_{3} / \mathrm{TiO}_{2}$ attained the RWGS equilibriumlimited $\mathrm{CO}$ yield at $\geq 465{ }^{\circ} \mathrm{C}$ (denoted by the black dashed line). Notably, $\mathrm{TiO}_{2}$ is partially reduced under the $\mathrm{H}_{2}$-rich atmosphere used in these experiments. A reducible support is not beneficial for carbonate-catalyzed RWGS, however, as seen by the results using an irreducible $\mathrm{Al}_{2} \mathrm{O}_{3}$
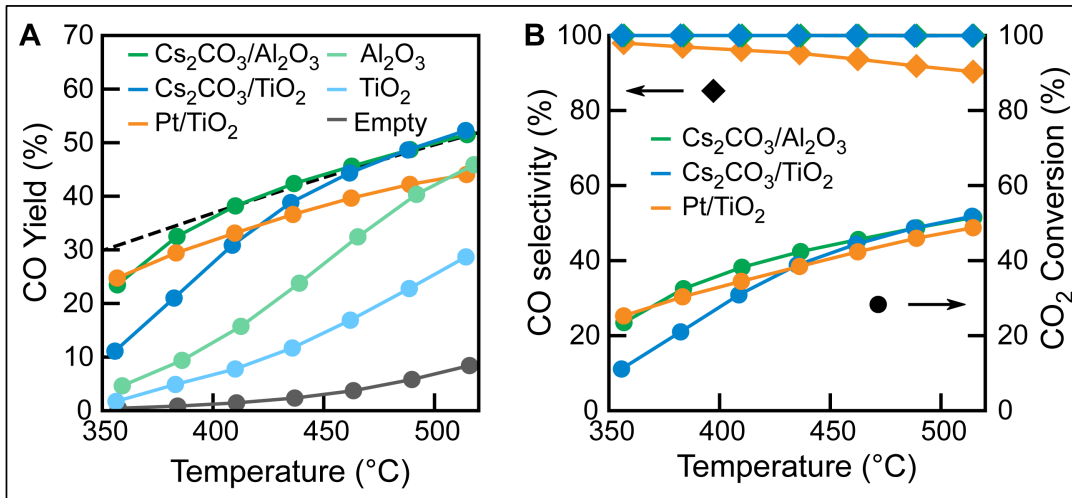

Figure 4: Catalyst comparison and temperature dependence. A) CO yield vs temperature at $40 \mathrm{sccm}$ of $3: 1 \mathrm{H}_{2}: \mathrm{CO}_{2}\left(\mathrm{WHSV}=4800 \mathrm{ml} \mathrm{g}^{-1} \mathrm{~h}^{-1}\right), 10$ bar. Each temperature is held for $3 \mathrm{~h}$. Equilibrium RWGS CO yield is indicated by the dashed black line. B) $\mathrm{CO}$ selectivity and total $\mathrm{CO}_{2}$ conversion vs temperature. Note that both dispersed carbonate catalysts are overlapping at nearly $100 \%$ CO selectivity.

support. The unloaded $\gamma-\mathrm{Al}_{2} \mathrm{O}_{3}$ support itself showed considerably higher $\mathrm{CO}$ production than unloaded $\mathrm{TiO}_{2}$, but did not reach the equilibrium-limited yield even at $515{ }^{\circ} \mathrm{C}$. The $\mathrm{Cs}_{2} \mathrm{CO}_{3} / \mathrm{Al}_{2} \mathrm{O}_{3}$ catalyst was substantially more active than $\mathrm{Cs}_{2} \mathrm{CO}_{3} / \mathrm{TiO}_{2}$, reaching the equilibrium-limited $\mathrm{CO}$ yield at $\geq 410{ }^{\circ} \mathrm{C}$. Both $\mathrm{Cs}_{2} \mathrm{CO}_{3} / \mathrm{TiO}_{2}$ and $\mathrm{Cs}_{2} \mathrm{CO}_{3} / \mathrm{Al}_{2} \mathrm{O}_{3}$ showed essentially $100 \%$ selectivity for $\mathrm{CO}$ (Table S2).

An oxide support is not essential for carbonate-catalyzed RWGS. Whereas a GAC support showed no increase in $\mathrm{CO}$ production relative to the empty reactor, the $\mathrm{Cs}_{2} \mathrm{CO}_{3} / \mathrm{GAC}$ catalyst came close to the equilibrium-limited $\mathrm{CO}$ yield (within a few percentage points) at $\geq 450{ }^{\circ} \mathrm{C}$ (Fig. S3). $\mathrm{Cs}_{2} \mathrm{CO}_{3} / \mathrm{GAC}$ was less active than $\mathrm{Cs}_{2} \mathrm{CO}_{3} / \mathrm{TiO}_{2}$ or $\mathrm{Cs}_{2} \mathrm{CO}_{3} / \mathrm{Al}_{2} \mathrm{O}_{3}$, but the carbonate loading was substantially lower in $\mathrm{Cs}_{2} \mathrm{CO}_{3} / \mathrm{GAC}\left(10 \mathrm{wt} \%\right.$ vs $23-34 \mathrm{wt} \%$ ) because of the need to use a methanolic $\mathrm{Cs}_{2} \mathrm{CO}_{3}$ solution with this more hydrophobic support. Increasing the loading would likely improve the performance with this material.

For performance comparison with transition metal-catalyzed RWGS, a commercial platinum nanoparticle catalyst ( $1 \mathrm{wt} . \% \mathrm{Pt} / \mathrm{TiO}_{2}$ ) was examined. To our knowledge, $\mathrm{Pt} / \mathrm{TiO}_{2}$ is the most active previously reported RWGS catalyst (on a mol CO per g catalyst per s basis) in the $300-500{ }^{\circ} \mathrm{C}$ range ${ }^{23}$ As seen in Fig. $4 \mathrm{~A}$, the commercial $\mathrm{Pt} / \mathrm{TiO}_{2}$ catalyst showed considerable RWGS catalysis at all temperatures examined. In contrast to $\mathrm{Cs}_{2} \mathrm{CO}_{3} / \mathrm{TiO}_{2}$ and $\mathrm{Cs}_{2} \mathrm{CO}_{3} / \mathrm{Al}_{2} \mathrm{O}_{3}$, however, $\mathrm{Pt} / \mathrm{TiO}_{2}$ never reaches the equilibrium-limited $\mathrm{CO}$ yield because of competitive $\mathrm{CH}_{4}$ formation. Fig. 4B compares the $\mathrm{CO}_{2}$ conversion and selectivity for $\mathrm{CO}$ vs temperature for $\mathrm{Pt} / \mathrm{TiO}_{2}, \mathrm{Cs}_{2} \mathrm{CO}_{3} / \mathrm{TiO}_{2}$, and $\mathrm{Cs}_{2} \mathrm{CO}_{3} / \mathrm{Al}_{2} \mathrm{O}_{3}$. Whereas the dispersed $\mathrm{Cs}_{2} \mathrm{CO}_{3}$ catalysts are essentially $100 \%$ selectivity for $\mathrm{CO}$ across all temperatures, $\mathrm{Pt} / \mathrm{TiO}_{2}$ shows increasing $\mathrm{CH}_{4}$ production as the temperature is increased, reaching $\sim 5 \%\left(10 \%\right.$ of $\mathrm{C}_{1}$ products $)$ at $515{ }^{\circ} \mathrm{C}$. The exothermic methanation of $\mathrm{CO}_{2} / \mathrm{CO}$ (Eq. 2) is a common competing reaction pathway for RWGS catalysts. The absence of $\mathrm{CH}_{4}$ with dispersed carbonate catalysts is consistent with the notion that the low $\mathrm{CO}$ affinity of $\mathrm{Cs}^{+}$precludes further reduction.

To assess their stability, $\mathrm{Cs}_{2} \mathrm{CO}_{3} / \mathrm{Al}_{2} \mathrm{O}_{3}$ and $\mathrm{Pt} / \mathrm{TiO}_{2}$ were compared in $44 \mathrm{~h}$ reactions performed under the same flowing conditions $\left(3: 1 \mathrm{H}_{2}: \mathrm{CO}_{2}, 10\right.$ bar, 4,800 WHSV) at $468{ }^{\circ} \mathrm{C} . \mathrm{Cs}_{2} \mathrm{CO}_{3} / \mathrm{Al}_{2} \mathrm{O}_{3}$ maintained the equilibrium-limited $\mathrm{CO}$ yield without producing $\mathrm{CH}_{4}$ for the entire run, with no detectable degradation in performance (Fig. 5A). In contrast, with $\mathrm{Pt} / \mathrm{TiO}_{2}$ the $\mathrm{CH}_{4}$ increased after $\sim 12 \mathrm{~h}$ on stream, rising from an initial level of $\sim 2.4 \%$ yield to a final level of $\sim 6 \%$. The rise in $\mathrm{CH}_{4}$ yield was coupled with a corresponding reduction in $\mathrm{CO}$ yield. This result suggests that there are rearrangements of the Pt nanoparticles on the 
multi-hour timescale that change the distribution of active sites, which is a common phenomenon for transition metal nanoparticle-based catalysts. ${ }^{42-}$ 45

Finally, the effect of sulfurcontaining impurities was assessed by performing a $68 \mathrm{~h}$ stability test with a gas mixture in which $50 \mathrm{ppm}$ of $\mathrm{H}_{2} \mathrm{~S}$ gas was introduced into the $1: 3 \quad \mathrm{CO}_{2}: \mathrm{H}_{2}$ feed (Fig. 5B). For $\mathrm{Pt} / \mathrm{TiO}_{2}$, the presence of $\mathrm{H}_{2} \mathrm{~S}$ primarily attenuated $\mathrm{CH}_{4}$ formation such that $\sim 2 \% \quad \mathrm{CH}_{4}$ yield was maintained throughout the run. In
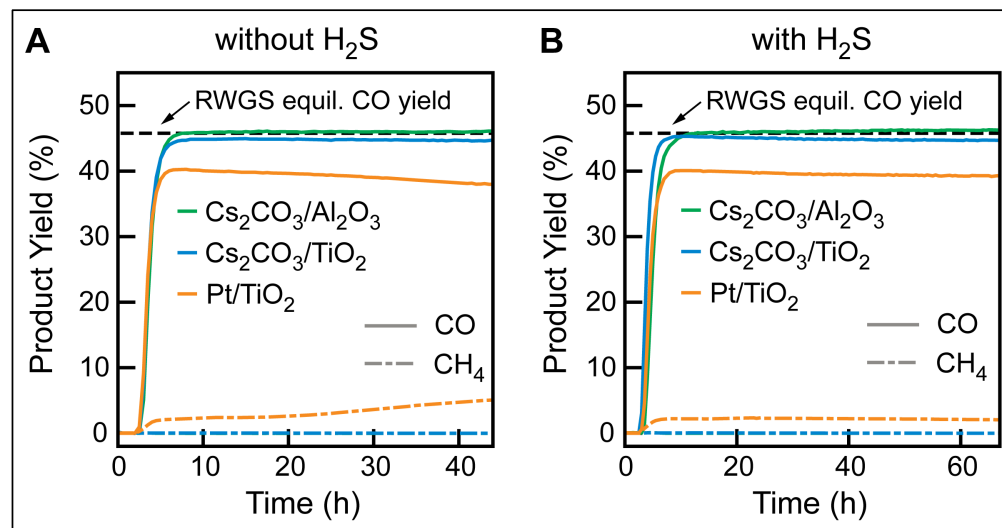

Figure 5: Stability tests. A) Product yields vs time for dispersed carbonate and $\mathrm{Pt} / \mathrm{TiO}_{2}$ catalysts for long-duration run at $40 \mathrm{sccm}$ of 3:1 $\mathrm{H}_{2}: \mathrm{CO}_{2}$ (WHSV $\left.=4800 \mathrm{ml} \mathrm{g}^{-1} \mathrm{~h}^{-1}\right), 10 \mathrm{bar}, 468^{\circ} \mathrm{C}$; B) Product yields vs time under same conditions but with $50 \mathrm{ppm} \mathrm{H}_{2} \mathrm{~S}$ added to gas stream.

addition, the $\mathrm{CO}$ yield showed a slow decline from $40 \%$ to $\sim 39 \%$ over the course of the run. Since the $\mathrm{CH}_{4}$ production is essentially constant, we attribute this decline to a slow poisoning of the RWGS sites on the $\mathrm{Pt}$ particles, which is consistent with other studies of $\mathrm{H}_{2} \mathrm{~S}$ effects on Pt catalysts. In contrast, the performance of $\mathrm{Cs}_{2} \mathrm{CO}_{3} / \mathrm{Al}_{2} \mathrm{O}_{3}$ was completely unaffected by $\mathrm{H}_{2} \mathrm{~S}$, with $100 \%$ selective, equilibrium-limited $\mathrm{CO}$ production maintained for the entire run.

We anticipate that other inorganic bases as well as different cations can be used to achieve robust and selective RWGS catalysis provided the materials are adequately dispersed in a support that is compatible with these conditions. Tailoring the support pore volume and surface area to enable maximal loading of dispersed bases is a straightforward strategy to maximizing RWGS activity. The ability to utilize different support materials also provides flexibility to tailor other catalyst properties relevant to industrial application such as thermal conductivity.

\section{Estimation of Accessible Power-to-Alcohol Energy Efficiency}

The demonstration of robust carbonate-catalyzed RWGS activity under application-relevant conditions motivates a preliminary assessment of the accessible energy conversion efficiency for a power-to-ethanol system that utilizes this technology (Fig. 1A, Electrolysis + RWGS). An estimate can be made by examining the energy requirements for each of the primary process steps: 1) electrolytic $\mathrm{H}_{2}$ production, 2) RWGS, 3) fermentation, and 4) isolation of the product via distillation. Based on our results above, we assume a 1:1:5 $\mathrm{CO}: \mathrm{CO}_{2}: \mathrm{H}_{2}$ gas ratio output from the RWGS unit operating at the equilibrium-limited $\mathrm{CO}_{2}$ conversion at $\sim 500{ }^{\circ} \mathrm{C}$. Commercial PEM electrolyzers operate at $80 \%$ efficiency, requiring $364 \mathrm{~kJ} \mathrm{~mol}^{-1} \mathrm{H}_{2}$ generated. $^{18}$ The RWGS unit must supply the reaction enthalpy of $37.1 \mathrm{~kJ} \mathrm{~mol}^{-1} \mathrm{CO}$ produced at $500{ }^{\circ} \mathrm{C}$. At the required process temperature, industrial electric heaters can approach $100 \%$ efficiency. ${ }^{46}$ Based on the reported emissions intensity of acetogenic fermentation of syngas to ethanol, ${ }^{47}$ estimates for utilities requirements and energy recovery place the total energy requirement for fermentation and distillation at $0.39 \mathrm{MJ} \mathrm{mol}^{-1}$ ethanol. Accounting for the carbon efficiency of fermentation $(91 \%)^{47}$ and adjusting for the stoichiometry of ethanol production (i.e. $6 \mathrm{~mol} \mathrm{H}_{2}$ required per $1 \mathrm{~mol} \mathrm{CO}$ produced via RWGS), the total baseline power requirement for the system is estimated at $2.82 \mathrm{MJ} \mathrm{mol}^{-1}$ ethanol, corresponding to a $48.5 \%$ efficiency for power to fuel grade ethanol (see Supporting Information for further details).

A similar approach can be used to analyze the efficiency of a system that uses $\mathrm{CO}_{2}$ electrolysis instead of RWGS to supply the requisite CO for gas fermentation (Fig. 1A, Dual Electrolysis). The basic steps of this 
system are 1) electrolytic CO production, 2) PEM electrolysis to provide $\mathrm{H}_{2}, 3$ ) fermentation, and 4) isolation of the product fuel (note that steps 3 and 4 are the same as those for the RWGS process outlined above). For a direct comparison, we again assume a 1:1:5 CO: $\mathrm{CO}_{2}: \mathrm{H}_{2}$ gas ratio supplied to the fermentation unit. State-of-the-art reported performance for low-temperature $\mathrm{CO}_{2}$ electrolysis has been achieved using a gas diffusion electrode (GDE) cell containing an anion exchange membrane. Under steady-state conditions, this cell operates at $200 \mathrm{~mA} \mathrm{~cm}{ }^{-2}$ with a full-cell potential of $3 \mathrm{~V}$ and a CO Faradaic efficiency of $98 \%$, corresponding to an energy requirement of $0.60 \mathrm{MJ} \mathrm{mol}^{-1} \mathrm{CO}^{48} \mathrm{~A}$ small amount of $\mathrm{H}_{2}(0.02 \mathrm{~mol}$ per mol $\mathrm{CO}$ ) is co-produced in the electrolysis. The remaining $4.98 \mathrm{~mol} \mathrm{H}_{2}$ that must be supplied for each mole of electrogenerated $\mathrm{CO}$ can be supplied by the PEM electrolyzer, corresponding to an energy demand of 1.81 $\mathrm{MJ} \mathrm{mol}^{-1}$ ethanol. As before, the energy requirement for fermentation and distillation is $0.39 \mathrm{MJ} \mathrm{mol}^{-1}$ ethanol. In total, the energy demand for the process comes to $2.86 \mathrm{MJ} \mathrm{mol}^{-1}$ ethanol, representing an overall power-to-fuel efficiency of $47.9 \%$.

While this high-level analysis indicates that their accessible energy efficiencies are comparable, the RWGS approach utilizing the carbonate catalysts described here has substantial advantages over a system that utilizes $\mathrm{CO}_{2}$ electrolysis with respect to process complexity and scalability. Low-temperature $\mathrm{CO}_{2}$ electrolysis is currently in a lab/pre-pilot stage of development. ${ }^{14,49,50}$ State-of-the-art $\mathrm{CO}_{2}$ electrolyzers utilize specialized components that have never been produced at a large scale $\left(\mathrm{CO}_{2}\right.$ reduction gas diffusion electrodes and anion exchange membranes) and high loadings of precious metal anodic catalysts (e.g. $\mathrm{IrO}_{2}$ ) to minimize overpotential losses and avoid corrosion. ${ }^{48}$ Achieving efficient mass transport is uniquely challenging for a $\mathrm{CO}_{2}$ electrolyzer because it requires delivering a gaseous reactant and removing both gaseous $\left(\mathrm{CO}\right.$, unreacted $\left.\mathrm{CO}_{2}\right)$ and liquid $\left(\mathrm{H}_{2} \mathrm{O}\right)$ products. Given these complexities, $\mathrm{CO}_{2}$ electrolyzers are likely to cost at least as much as PEM water electrolzyers on a per-electrode area basis, but their $10 \times$ lower current density necessitates a $10 \times$ higher electrode area for the same current output. Finally, the coinage metals (typically $\mathrm{Ag}$ ) that are used as the cathodic catalyst for selective $\mathrm{CO}_{2}$ reduction to $\mathrm{CO}$ are irreversibly poisoned by low levels of $\mathrm{H}_{2} \mathrm{~S}$, which is produced in the fermentation reactor. Because the single-pass conversion of gas fermentation is not $100 \%$, recycle loops are needed to avoid wasting carbon. The recycle stream would need to be desulfurized to a very low level to feed the $\mathrm{CO}_{2}$ back into the $\mathrm{CO}_{2}$ electrolyzer, which adds considerable process complexity.

In contrast to $\mathrm{CO}_{2}$ electrolysis, the reactor design principles for large-scale, heterogeneously catalyzed gasphase processes are very well-established from many decades of their use in the chemical and fuel industries. The dispersed carbonate RWGS catalysts described here are trivial to prepare from readily available, non-precious materials (e.g. $\mathrm{Cs}_{2} \mathrm{CO}_{3}$ and $\gamma-\mathrm{Al}_{2} \mathrm{O}_{3}$ ). The $\mathrm{H}_{2} \mathrm{~S}$ tolerance of carbonate-catalyzed RWGS could obviate the need for desulfurization, reducing the overall process complexity and energy demand. While further testing will be needed to establish performance in larger reactors and over much longer durations, the performance already demonstrated with $\mathrm{Cs}_{2} \mathrm{CO}_{3} / \mathrm{Al}_{2} \mathrm{O}_{3}$ demonstrates no significant liabilities at this stage.

\section{Conclusions}

Acetogenic fermentation is a promising liquid fuel generation technique that currently relies on limited high-energy syngas sourced from biomass or steel mill exhaust. The above results demonstrate how carbonate-catalyzed RWGS can be used to remove this dependency by transforming $\mathrm{H}_{2}$ and $\mathrm{CO}_{2}$ into a suitable source. Dispersed carbonates can produce the necessary gas output via equilibrium-limited RWGS at useful space velocities for at least days of operation with no apparent degradation and no $\mathrm{H}_{2} \mathrm{~S}$ sensitivity. Additionally, such catalysts are trivial to synthesize and can be readily scaled for rapid deployment. These results provide a compelling case for utilizing carbonate-catalyzed RWGS to bridge the gap between $\mathrm{H}_{2}$ 
and gas fermentation to ethanol or other $\mathrm{C}_{2+}$ alcohols as fermentation technology develops. By upgrading the alcohol products to jet fuel, this strategy could be used to produce sustainable aviation fuel without harvesting biomass.

\section{Acknowledgements}

We thank the U.S. Department of Energy (DE-SC0020394) and the TomKat Center for Sustainable Energy for support of this research. A.D.F. acknowledges support from a NASA Space Technology Research Fellowship. Characterization studies were performed at the Stanford Nano Shared Facilities (SNSF), supported by the National Science Foundation under award ECCS-1542152.

\section{Declaration of Interests}

The authors have filed a provisional patent application based on the catalysts described in this work.

\section{References}

$1 \quad$ U.S. Energy Information Administration. International Energy Outlook 2021.

2 Majumdar, A. \& Deutch, J. Research opportunities for $\mathrm{CO}_{2}$ utilization and negative emissions at the gigatonne scale. Joule 2, 805-809 (2018).

3 Barber, J. Photosynthetic energy conversion: natural and artificial. Chem. Soc. Rev. 38, 185-196 (2009).

4 Marlin, D. S., Sarron, E. \& Sigurbjörnsson, Ó. Process advantages of direct $\mathrm{CO}_{2}$ to methanol synthesis. Frontiers in Chemistry 6, 446 (2018).

5 Dieterich, V., Buttler, A., Hanel, A., Spliethoff, H. \& Fendt, S. Power-to-liquid via synthesis of methanol, DME or Fischer-Tropsch-fuels: a review. Energy Environ. Sci. 13, 3207-3252 (2020).

6 Bengelsdorf, F. R. et al. in Advances in applied microbiology Vol. 103, 143-221 (Elsevier, 2018).

7 Gehrmann, S. \& Tenhumberg, N. Production and Use of Sustainable $\mathrm{C}_{2}-\mathrm{C}_{4}$ Alcohols - An Industrial Perspective. Chemie Ingenieur Technik 92, 1444-1458 (2020).

8 Wang, W.-C. et al. Review of Biojet Fuel Conversion Technologies. (United States, 2016).

9 Molitor, B. et al. Carbon recovery by fermentation of CO-rich off gases-turning steel mills into biorefineries. Bioresour. Technol. 215, 386-396 (2016).

10 Mock, J. et al. Energy conservation associated with ethanol formation from $\mathrm{H}_{2}$ and $\mathrm{CO}_{2}$ in Clostridium autoethanogenum involving electron bifurcation. J. Bacteriol. 197, 2965-2980 (2015).

11 Heffernan, J. K. et al. Enhancing $\mathrm{CO}_{2}$-Valorization Using Clostridium autoethanogenum for sustainable fuel and chemicals production. Front. Bioeng. Biotechnol. 8, 204 (2020).

12 Ciliberti, C. et al. Syngas derived from lignocellulosic biomass gasification as an alternative resource for innovative bioprocesses. Processes 8, 1567 (2020).

13 Haas, T., Krause, R., Weber, R., Demler, M. \& Schmid, G. Technical photosynthesis involving CO 2 electrolysis and fermentation. Nat. Catal. 1, 32 (2018).

14 Krause, R. et al. Industrial Application Aspects of the Electrochemical Reduction of $\mathrm{CO}_{2}$ to $\mathrm{CO}$ in Aqueous Electrolyte. Chemie Ingenieur Technik 92, 53-61 (2020).

15 Stoll, I. K., Boukis, N. \& Sauer, J. Syngas Fermentation to Alcohols: Reactor Technology and Application Perspective. Chemie Ingenieur Technik 92, 125-136 (2020).

16 Köpke, M. \& Simpson, S. D. Pollution to products: recycling of 'above ground' carbon by gas fermentation. Curr. Opin. Biotechnol. 65, 180-189 (2020).

17 Carmo, M., Fritz, D. L., Mergel, J. \& Stolten, D. A comprehensive review on PEM water electrolysis. Int. J. Hydrog. Energy 38, 4901-4934 (2013).

18 Ayers, K. The potential of proton exchange membrane-based electrolysis technology. Curr. Opin. Electrochem. 18, 9-15 (2019). 
19 Häussinger, P., Lohmüller, R. \& Watson, A. M. Hydrogen, 2. Production. in Ullmann's Encyclopedia of Industrial Chemistry (Wiley-VCH Verlag GmbH \& Co. KGaA, 2011).

20 Fuglestvedt, J. S. et al. Transport impacts on atmosphere and climate: Metrics. Atmos. Environ. 44, 4648-4677 (2010).

$21 \mathrm{Xu}, \mathrm{Y} ., \mathrm{Isom}, \mathrm{L}$. \& Hanna, M. A. Adding value to carbon dioxide from ethanol fermentations. Bioresour. Technol. 101, 3311-3319 (2010).

22 Daza, Y. A. \& Kuhn, J. N. $\mathrm{CO}_{2}$ conversion by reverse water gas shift catalysis: comparison of catalysts, mechanisms and their consequences for $\mathrm{CO}_{2}$ conversion to liquid fuels. $R S C A d v$. 6 , 49675-49691 (2016).

23 Kim, S. S., Lee, H. H. \& Hong, S. C. The effect of the morphological characteristics of $\mathrm{TiO}_{2}$ supports on the reverse water-gas shift reaction over $\mathrm{Pt} / \mathrm{TiO}_{2}$ catalysts. Appl. Catal. B 119, 100108 (2012).

24 Liu, X., Pajares, A., Calinao Matienzo, D. J. D., Ramírez de la Piscina, P. \& Homs, N. Preparation and characterization of bulk Mox catalysts and their use in the reverse water-gas shift reaction. Catalysis Today 356, 384-389 (2020).

25 Morse, J. R., Juneau, M., Baldwin, J. W., Porosoff, M. D. \& Willauer, H. D. Alkali promoted tungsten carbide as a selective catalyst for the reverse water gas shift reaction. $J \mathrm{CO}_{2}$ Util. 35, 3846 (2020).

26 Juneau, M. et al. Assessing the viability of $\mathrm{K}-\mathrm{Mo}_{2} \mathrm{C}$ for reverse water-gas shift scale-up: molecular to laboratory to pilot scale. Energy Environ. Sci. 13, 2524-2539 (2020).

27 Schaidle, J. A., Lausche, A. C. \& Thompson, L. T. Effects of sulfur on $\mathrm{Mo}_{2} \mathrm{C}$ and $\mathrm{Pt} / \mathrm{Mo}_{2} \mathrm{C}$ catalysts: Water gas shift reaction. J. Catal. 272, 235-245 (2010).

28 Park, S.-W., Joo, O.-S., Jung, K.-D., Kim, H. \& Han, S.-H. ZnO/Cr $\mathrm{O}_{3}$ catalyst for reverse-watergas-shift reaction of CAMERE process. Korean J. Chem. Eng. 17, 719-722 (2000).

29 Wood, B. J., Isakson, W. E. \& Wise, H. Kinetic studies of catalyst poisoning during methanol synthesis at high pressures. Ind. Eng. Chem. Prod. Res. Dev. 19, 197-204 (1980).

30 Valsamakis, I. \& Flytzani-Stephanopoulos, M. Sulfur-tolerant lanthanide oxysulfide catalysts for the high-temperature water-gas shift reaction. Appl. Catal. B 106, 255-263 (2011).

31 Osaki, T. et al. Kinetics of reverse water gas shift (RWGS) reaction on metal disulfide catalysts. $J$. Mol. Catal. A Chem. 125, 63-71 (1997).

32 Xiao, D. J. et al. A closed cycle for esterifying aromatic hydrocarbons with $\mathrm{CO}_{2}$ and alcohol. Nat. Chem. 11, 940-947 (2019).

33 Anslyn, E. V. \& Dougherty, D. A. Modern physical organic chemistry. (University Science Books, 2006).

34 Hadjiivanov, K. I. \& Vayssilov, G. N. Characterization of oxide surfaces and zeolites by carbon monoxide as an IR probe molecule. Adv. Catal. 47, 307-511 (2002).

35 Kaeser, J. A., Tanaka, J., Douglass, J. C. \& Hill, R. D. Hydrosulfides of group I and group II metals. Inorg. Chem. 12, 3019-3020 (1973).

36 Licht, S. Aqueous solubilities, solubility products and standard oxidation-reduction potentials of the metal sulfides. J. Electrochem. Soc. 135, 2971-2975 (1988).

37 Amenomiya, Y. \& Pleizier, G. Alkali-promoted alumina catalysts. 2. Water-gas shift reaction. $J$. Catal. 76, 345-353 (1982).

38 Amenomiya, Y. Active sites of solid acidic catalysts: II. Water-gas conversion on alumina and some other catalysts. J. Catal. 55, 205-212 (1978).

39 Banerjee, A. \& Kanan, M. W. Carbonate-promoted $\mathrm{CO}_{2}$ hydrogenation to multi-carbon oxygenates. ACS Cent. Sci. 4, 606-613 (2018).

40 Busca, G. \& Lorenzelli, V. Infrared spectroscopic identification of species arising from reactive adsorption of carbon oxides on metal oxide surfaces. Materials Chemistry 7, 89-126 (1982).

41 Kantschewa, M., Albano, E., Ertl, G. \& Knozinger, H. Infrared and x-ray photoelectronspectroscopy study of $\mathrm{K}_{2} \mathrm{CO}_{3} / \gamma-\mathrm{Al}_{2} \mathrm{CO}_{3}$. Appl. Catal. 8, 71-84 (1983). 
42 Rodriguez, J. A. \& Hrbek, J. Interaction of sulfur with well-defined metal and oxide surfaces: unraveling the mysteries behind catalyst poisoning and desulfurization. Acc. Chem. Res. 32, 719728 (1999).

43 Bartholomew, C. H. Mechanisms of catalyst deactivation. Appl. Catal. A 212, 17-60 (2001).

44 Wang, X., Gorte, R. J. \& Wagner, J. P. Deactivation mechanisms for Pd/ceria during the watergas-shift reaction. J. Catal. 212, 225-230 (2002).

45 Goguet, A. et al. Study of the origin of the deactivation of a $\mathrm{Pt} / \mathrm{CeO}_{2}$ catalyst during reverse water gas shift (RWGS) reaction. J. Catal. 226, 382-392 (2004).

46 Perkin, R. M. in Ullmann's Encyclopedia of Industrial Chemistry (Wiley-VCH Verlag GmbH \& Co. KGaA, 2012).

47 Handler, R. M., Shonnard, D. R., Griffing, E. M., Lai, A. \& Palou-Rivera, I. Life cycle assessments of ethanol production via gas fermentation: anticipated greenhouse gas emissions for cellulosic and waste gas feedstocks. Ind. Eng. Chem. Res. 55, 3253-3261 (2016).

48 Liu, Z., Yang, H., Kutz, R. \& Masel, R. I. $\mathrm{CO}_{2}$ electrolysis to $\mathrm{CO}$ and $\mathrm{O}_{2}$ at high selectivity, stability and efficiency using Sustainion membranes. J. Electrochem. Soc. 165, J3371 (2018).

49 Rabinowitz, J. A. \& Kanan, M. W. The future of low-temperature carbon dioxide electrolysis depends on solving one basic problem. Nat Commun 11, 5231 (2020).

50 Küngas, R. Electrochemical $\mathrm{CO}_{2}$ Reduction for CO Production: Comparison of Low-and HighTemperature Electrolysis Technologies. J. Electrochem. Soc. 167, 044508 (2020). 